\title{
entrevista
}

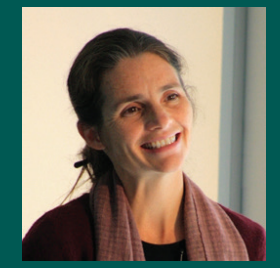

\section{SABINA ALKIRE}

Por Paula Montagner

Sabina Alkire dirige a Iniciativa de Pobreza e Desenvolvimento Humano da Universidade de Oxford (OPHI), um centro de pesquisas que integra o Departamento de Desenvolvimento Internacional da prestigiosa Universidade de Oxford no Reino Unido. Suas pesquisas incluem as medidas de pobreza multidimensional, bem-estar econômico, medidas de liberdade e desenvolvimento humano, além de ações de construção de capacidades institucionais em organizações e comunidades.

Sabina esteve no Brasil em agosto de 2014, participando da Oficina Técnica "Dimensionamento e caracterização da pobreza no contexto de sua superação: os limites dos indicadores clássicos e as novas propostas metodológicas". Essa oficina, promovida pelos integrantes da Iniciativa Brasileira por um Mundo Sem Pobreza / World Without Poverty - Brazil Learning Initiative (www. wwp.org.br), teve como objetivo discutir os aspectos metodológicos da mensuração de indicadores de pobreza, seus limites e a precisão estatística. Ela concedeu à RBMA uma entrevista em que detalha seu percurso na construção do Indice de Pobreza Multidimensional.

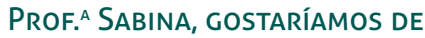
CONHECER UM POUCO DA SUA MOTIVAÇÃO PARA REALIZAR ESTUDOS SOBRE O TEMA DA POBREZA E DE ELABORAÇÃO DE METODOLOGIAS SOBRE A MENSURAÇÃO DO TEMA? Bem, minha motivação fundamental para o trabalho foi a preocupação em ter medidas que reflitam o que as pessoas vivenciam. Fiz meu doutorado considerando tanto os trabalhos de Amartya Sen quanto o papel da abordagem participativa para a compreensão mais aprofundada das situações de pobreza. Desde então, tenho estudado a literatura participativa, sobre como ajudar as pessoas pobres a encontrar formas de explicitar situações de pobreza e privação ou que buscam alcançar situações de maior bem-estar. Já posso adiantar que o que é comum nas definições que as pessoas constroem é que a pobreza não está restrita à falta de rendimento monetário ou à falta de renda. Sempre há várias coisas dando errado ao mesmo tempo, e parte da ansiedade e da tensão das pessoas em situação de pobreza tende a ser agrupada no contexto das privações. Há muitos aspectos a considerar quando elas falam sobre o que entendem sobre pobreza: falta de 
trabalho, a casa que não funciona, o homem que não tem saúde, etc., isso significa que a pobreza de fato afeta as pessoas, em muitos níveis. Ora, quando medimos, por muitas razões, tendemos a nos focar apenas no aspecto monetário. Temos de ter em mente, no entanto, que o valor monetário simplifica o conjunto de carências que estão presentes na vida das pessoas, e isto é muito importante também para dar aos legisladores, funcionando como um incentivo para compreender a necessidade de reduzir todas as outras privações, portanto como uma boa aproximação dos estados de pobreza para serem identificados, e com isso mudar a vida das pessoas pobres.

Eu fui mais para o lado empírico do trabalho e encontramos que, com frequência, mas não sempre, é necessário verificarmos cuidadosamente cada contexto. Com frequência, a pobreza monetária não identifica as mesmas pessoas quando consideramos as outras dimensões da pobreza. É claro que há algumas delas. Sempre há algumas delas. Apenas para dar um exemplo, fizemos um estudo em 11 países e identificamos pessoas que são pobres segundo os indicadores da pobreza multidimensional e comparamos a porcentagem das pessoas abaixo da linha de pobreza monetária. Encontramos, por exemplo, na África do Sul, enquanto 11\% da população era pobre segundo critérios de renda, quando considerados os critérios da pobreza multidimensional, apenas 3\% era pobre nos dois métodos de mensuração. No Vietnã, enquanto cerca de $16 \%$ da população era pobre segundo o critério monetário, 7\% era pobre nas duas formas de medir. Portanto, encontramos que, por diferentes razões, erros de medição, atribuições de status, presença de pessoa com deficiência no domicílio ou família, entre outros, levam a que esta família precise de mais dinheiro. Encontramos outros problemas, tais como problemas de dependência química, preços locais de bens básicos muito diferentes do valor médio observado nas pesquisas nacionais ou regionais de preço. Por diferentes razões, a pobreza não era identificada nas mesmas pessoas. Isto nos deu uma razão para considerarmos importante o olhar multidimensional da pobreza. 
COM QUAIS DIMENSÕES A METOdOLOGIA DESENVOLVIDA PELA EOUIPE E POR VOCÊ SÃO MAIS COMUNS E MAIS TRABALHADAS NOS DIVERSOS PAÍSES PARA OS OUAIS HÁ ESTUDOS?

No estudo usamos muitos bancos de dados diferentes. Nós não podíamos usar as mesmas dimensões. Às vezes usamos saúde, educação e padrões de vida, às vezes acrescentamos emprego, às vezes adicionamos ou dividimos em moradia e serviços, em vez de apenas padrões de vida, às vezes usamos renda na medida. No Iraque, por exemplo, usamos renda na medida de pobreza multidimensional e renda de custo de vida. Porém, isso estima uma correspondência muito, muito baixa entre as duas medidas, pois a renda na medida de pobreza multidimensional apenas pesa $20 \%$. Esta é uma das razões e as outras mudam com o tempo. Em nível global, fizemos um estudo com 34 países e observamos as mudanças na medida de pobreza multidimensional e as mudanças na pobreza, e não encontramos uma tendência clara. Vale destacar que os estudos revelaram uma redução mais rápida em Bangladesh e em Uganda da pobreza a partir do uso dos indicadores multidimensionais.

QUAIS AS PRINCIPAIS CAUSAS EXTERNAS A CONSIDERAR NA MEDIÇÃO DA POBREZA MULTIDIMENSIONAL?

Em primeiro lugar, o papel da decisão política, mas também o papel desempenhado por outros stakeholders, outros atores setoriais precisa ser considerado como parte da solução do problema. Claramente, há uma elasticidade entre o crescimento econômico e a pobreza. Outros autores já fizeram estudos que mostram que não basta atuar com a renda. o que reduz a pobreza multidimensional parece ser a ação de políticas setoriais, assim investimentos em saúde, educação, infraestrutura, sempre considerando que deve haver meta para as intervenções.

\section{O ACESSO A SERVIÇOS PÚBLICOS} BÁSICOS OQUE NEM SEMPRE ALCANÇAM OS GRUPOS E COMUNIDADES MAIS POBRES É CONSIDERADO UMA VARIÁVEL TAMBÉM?

Acesso a serviços não necessariamente é visível na medida de pobreza, depende de como você estima, ou você coloca o valor de seus preços em serviços. Por 
exemplo, no caso das Filipinas, o ministro Arsenio Balisacan promoveu o uso de medidas multidimensionais para a pobreza nas Filipinas, pois havia crescimento econômico elevado, mas a pobreza não está diminuindo. Nesse caso eles estão de fato usando muito dos frutos do seu crescimento em ações políticas, conseguindo assim o objetivo da diminuição da pobreza. Nem sempre a pobreza diminui quando ocorre crescimento econômico, mas por vezes o crescimento decorre das ações que levam à diminuição da pobreza multidimensional. Depende mesmo de como os benefícios do crescimento são investidos e distribuídos.

\section{COMO FOI CONSTITUÍDA A NOVA} METODOLOGIA DE ABORDAGEM DAS PESSOAS PARA REVELAR OUAIS SÃO AS INFORMAÇÕES OU OS ASPECTOS RELEVANTES EM CADA SITUAÇÃO? QUUAS SÃO AS PRINCIPAIS MOTIVAÇÕES PARA O DESENVOLVIMENTO DESTE TIPO DE ABORDAGEM?

James Foster é o coautor da maior parte do porquê usamos a medida da pobreza, os estudos de Foster respaldam o índice de pobreza multidimensional. Quando ele fez uma palestra sobre pobreza crôni- ca em 2006, eu estava procurando uma maneira de medir a pobreza considerando outras variáveis que não apenas renda, e isso se desdobrou em uma metodologia que pôde incorporar a presença ou ausência de todo tipo de informação e variáveis que envolvem algum aspecto da carência revelada pelas famílias. Veja por exemplo a presença ou ausência do acesso a água e ao saneamento, que não são variáveis cardinais, e sim variáveis categóricas. Assim, desenvolvemos uma metodologia que, como trabalhamos com pesquisa acadêmica, deve ser regressiva e axiomática e deve ter essa forma, mas que ao mesmo tempo utiliza todo tipo de indicação para alcançar seus objetivos.

Veja bem, o uso de outros tipos de informação não significa que tenhamos aberto mão do uso e do desenvolvimento de bases de dados. No início, fomos muito auxiliados pela colaboração com o governo do México, pois eles também estavam no processo de desenvolver uma medida nacional de pobreza multidimensional. Aprendemos muito ao discutirmos com eles como fazer 
a coleta de informação e criar indicadores para essas medidas. Também fizemos um pouco de trabalho de campo assim para o índice de pobreza multidimensional nacional, e nós partimos do estágio inicial da coleta das estatísticas nacionais nos vilarejos. Fizemos alguns testes de medidas usando estatísticas oficiais e comparamos a situação nacional e a situação da capital (Cidade do México). Tendo este olhar, fizemos visitas e conversas com as pessoas que vivem nas comunidades, debatemos sobre o significado do termo pobreza para eles, e implementamos uma pequena pesquisa, à noite nós calculamos como os dados que tínhamos obtido podiam afetar o índice obtido a partir das medidas oficiais da pobreza multidimensional, a partir da realidade observada nas comunidades visitadas. No dia seguinte, discutíamos com eles nosso entendimento do que eles nos tinham ensinado sobre a compreensão das dimensões da pobreza e assim ajustamos nossa compreensão em relação à compreensão sobre pobreza daquelas comunidades. Quem disse que é pobre, mas não aparece assim nas estatísticas também precisa ser entendido, pois ele sente algum tipo de carência que precisa ser incluído nas nossas medidas. Essa proximidade do público realmente nos ajudou a estabelecer uma sintonia fina e também a ver aspectos a serem focados nas medidas oficiais e nacionais.

EM SUA EXPERIÊNCIA, OUAL O VALOR DE TER UM ÍNDICE NACIONAL OUE COMBINA DIMENSÕES MULTIDIMENSIONAIS? QUAL O VALOR DE TÊ-LO EM CADA PAÍS?

Penso que o maior valor é para a política, um valor importante é a comunicação. Acho que a maior razão é o monitoramento e a avaliação. Assim, por exemplo, no governo da Colômbia, que tem um MPI (Índice de Pobreza Multidimensional) nacional. O MPI reflete seu plano de desenvolvimento nacional, e cada indicador está no plano nacional, cada recorte apresentado reflete um objetivo a ser alcançado, isto é, qual a meta para as áreas de educação, moradia, emprego, criança, adolescente e saúde. Com esse indicador, o presidente pode reunir seus ministros e analisar como cada área está atuando, e tenta fazer com que eles trabalhem juntos de forma coordenada e integrada. Assim, o que eles fazem é utilizar o MPI como alerta. Se 
os indicadores de pobreza estão altos, eles discutem, neste nível, o que podem fazer para tentar responder e reduzir esses indicadores nos próximos anos, e por meio de pesquisas atualizar anualmente os dados. A regularidade da informação atualizada é muito energizante, pois as pessoas veem imediatamente o resultado de seu trabalho.

Se você tem apenas a medida de pobreza e você é o ministro da Educação, que tem como meta ter todas as crianças na escola, mesmo aumentando a qualidade das escolas, os resultados do indicador de pobreza aparecerá daqui a 20 anos, quando essas crianças saírem da escola, encontrarem um trabalho, melhorarem e sua renda do trabalho. O que é importante para os indicadores de pobreza multidimensional é que eles mostram imediatamente, em um ano ou dois, se o esforço realizado está na direção certa e quais aspectos podem ser melhorados.

No BRASIL, AS POLÍtICAS PARA O ENFRENTAMENTO DA POBREZA CONSIDERAM NÃO APENAS UMA LINHA DE POBREZA MONETÁRIA, MAS MUITAS CARÊNCIAS ASSOCIADAS A SITUAÇÕES DE POBREZA. NO ENTANTO, POUCA ATENÇÃO FOI DADA AOS ÍNDICES SIN-
TÉTICOS, MUITAS VEZES ENTENDENDO QUE O GRAU DE DESIGUALDADES SÃO DIFERENCIADAS NAS REGIÕES E OUE, POR ISSO, DADOS MÉDIOS PODERIAM ESCONDER ALGUM ASPECTO LOCAL. ESTA PERCEPÇÃo NOS LEVOU A DESENVOLVER BOAS INFORMAÇÕES EM DIFERENTES BASES DE DADOS. COMO VOCÊ VÊ ESTE TIPO DE EXPERIÊNCIA? Primeiro, eu admiro o Brasil, e o Brasil faz as coisas de maneira diferente. Há economistas maravilhosos aqui, e muita criatividade, e muito compromisso com a troca com a sociedade civil, isto é uma combinação linda. Estou muito ansiosa por aprender mais sobre o que acontecerá aqui. Acho que o indicador sintético tem vantagens na comunicação mais fácil com o público, pelo menos esta tem sido nossa experiência. A partir do indicador nacional, é possível dizer que este é o nível de pobreza nacional, e propor como mudá-la, e podemos desagregá-la em diferentes regiões, assim como pode desagregar os diferentes indicadores. A imagem é de um origami em que podemos ver cada indicador em diferentes níveis - do nacional ao local. Para muitas comunidades, essas metas são mais fáceis de compreender porque colocamos em gráficos, temos animações, e temos infográficos, 
com histórias, histórias de pessoas e elas as entendem, pois podem ver esta pessoa, podem ver seu perfil, elas entendem. Números são muito abstratos, as pessoas veem outras pessoas e sua mudança de situação.

PESSOAS TÊM HISTÓRIAS MUITO PODEROSAS, ISSO REPRESENTA MUITO MAIS.V

Certamente. A outra coisa que quero dizer sobre a diversidade do Brasil é que há diferentes maneiras de lidar com isso, por exemplo, no México, foi a primeira vez que eles decompuseram sua medida por indígena e não indígena, assim eles usam a mesma medida e dividiram em grupo. Na Colômbia, eles decidiram fazer uma medida especial para a população indígena, e incluíram coisas que eram importantes para eles, como eles terem escola em seu próprio idioma. No Vietnã, que também é muito diverso, há governos locais fortes, eles estão discutindo como estão fazendo uma medida de pobreza multidimensional nacional, e estão discutindo a possibilidade de governos locais poderem ajustá-la para refletir as características regionais, e como ajustarão em uma estrutura ain- da será visto. O que posso dizer é que há diferentes experimentos em andamento. Estamos aprendendo muito, em certo sentido meu trabalho é admirá-los, aprender com a experiência de outros e compartilhar o que está acontecendo. Não há uma maneira certa de fazer essa medida, mas acho que mesmo quando apresentamos uma medida global a partir de 780 sub-regiões nacionais que já pesquisamos, e isto vale para os países mais pobres e não é o caso do Brasil. O que nos surpreende é que mesmo nesse nível de grande simplificação, ainda é possível ver diferenças que pessoas dentro dessas comunidades validam, no sentido de refletir, diferentes níveis de pobreza.

\section{VocÊ ACHA OQUE ESTAMOS NO MO-} MENTO EM OUE MAIS PAÍSES TENDEM A ABANDONAR APENAS AS MEDIDAS PURAMENTE ECONÔMICAS DE RENDA PARA CONSIDERAR ASPECTOS MULTIDIMENSIONAIS SOBRE A POBREZA?

Eu vejo uma verdadeira abertura. Há uma abertura em termos de superar a medida de pobreza calcada na renda de U\$1,25 ao dia, em razão da dificuldade com a paridade do poder de compra, assim é bem difícil traduzir diferentes países. Além disso, em âmbito nacio- 
nal, observamos a ampliação da demanda por medidas de pobreza multidimensional. Na Europa, estamos dialogando com países desenvolvidos para a exploração de medidas de pobreza nacional, e há muitos países de baixa renda que acabaram de ser formados para o uso desse tipo de indicadores.

Acho que há uma movimentação e, por diferentes razões, em algumas a renda não é precisa, ou não totalmente precisa, assim, por exemplo, essa não correspondência entre os dados econômicos e a situação social pode levar a altos níveis de exclusão social e isso não é aceitável. Você pode ser excluído de maneiras não monetárias, privado de sua dignidade como cidadão ao não poder participar das decisões, por exemplo. Outra razão é que o bem-estar é mais que dinheiro, por exemplo, Butão foi o segundo país a adotar o MPI, antes até da Colômbia em 2010, e é o país que tem um índice de felicidade nacional em elevação, e uma visão de mundo que não está dominada pela posse do dinheiro, mesmo que isto não signifique que não devam priorizar as populações mais carentes na busca de situações de melhor qualida- de para todos e em especial para os menos favorecidos.

VOCÊ DISSE QUE ESTAMOS NOS HABILITANDO E DEBATENDO MAIS OS ASPECTOS PARTICIPATIVOS DE NOSSAS POPULAÇÕES. COMO VOCÊ ENTENDE QUE MAIS CONHECIMENTO A PARTIR DE INDICADORES MULTIDIMENSIONAIS PODE AMPLIAR E MELHORAR A PARTICIPAÇÃO DA POPULAÇÃO?

Os países têm diferentes abordagens, mas El Salvador está no processo de construir o MIP nacional, eles têm 2 anos de encontros participativos, nos quais vão pelo país e dizem o que é pobreza, eles originalmente haviam definido 7 dimensões: emprego, moradia, educação, segurança, saúde, nutrição e renda. No entanto, no debate com a comunidade adicionaram o tema do lazer, havia demanda por um local onde as pessoas possam jogar, onde todos possam conversar e tomar um café. 0 governo disse que não é trabalho deles fornecer esse tipo de espaço, assim está havendo muitos diálogos interessantes. No Uruguai, está sendo interessante, pois eles sentaram-se à mesa com sindicatos e há diferentes partidos políticos, atores da sociedade civil, uma mesa bem diversa, tem sido muito rico, pois reunir essas perspectivas significa que as medidas finais são mais criativas. 